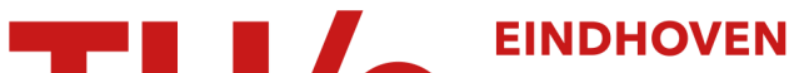 UNIVERSITY OF TECHNOLOGY
}

\section{Microfluidic actuation by modulation of surface stresses}

Citation for published version (APA):

Darhuber, A. A., Valentino, J. P., Davis, J. M., Troian, S. M., \& Wagner, S. (2003). Microfluidic actuation by modulation of surface stresses. Applied Physics Letters, 82(4), 657-659. https://doi.org/10.1063/1.1537512

DOI:

$10.1063 / 1.1537512$

Document status and date:

Published: 01/01/2003

\section{Document Version:}

Publisher's PDF, also known as Version of Record (includes final page, issue and volume numbers)

\section{Please check the document version of this publication:}

- A submitted manuscript is the version of the article upon submission and before peer-review. There can be important differences between the submitted version and the official published version of record. People interested in the research are advised to contact the author for the final version of the publication, or visit the $\mathrm{DOI}$ to the publisher's website.

- The final author version and the galley proof are versions of the publication after peer review.

- The final published version features the final layout of the paper including the volume, issue and page numbers.

Link to publication

\section{General rights}

Copyright and moral rights for the publications made accessible in the public portal are retained by the authors and/or other copyright owners and it is a condition of accessing publications that users recognise and abide by the legal requirements associated with these rights.

- Users may download and print one copy of any publication from the public portal for the purpose of private study or research.

- You may not further distribute the material or use it for any profit-making activity or commercial gain

- You may freely distribute the URL identifying the publication in the public portal.

If the publication is distributed under the terms of Article 25fa of the Dutch Copyright Act, indicated by the "Taverne" license above, please follow below link for the End User Agreement:

www.tue.nl/taverne

Take down policy

If you believe that this document breaches copyright please contact us at:

openaccess@tue.nl

providing details and we will investigate your claim. 


\title{
Microfluidic actuation by modulation of surface stresses
}

\author{
Anton A. Darhuber, Joseph P. Valentino, Jeffrey M. Davis, and Sandra M. Troian ${ }^{a)}$ \\ Microfluidic Research and Engineering Laboratory, Department of Chemical Engineering, \\ Princeton University, Princeton, New Jersey 08544 \\ Sigurd Wagner \\ Department of Electrical Engineering, Princeton University, Princeton, New Jersey 08544
}

(Received 26 June 2002; accepted 21 November 2002)

\begin{abstract}
We demonstrate the active manipulation of nanoliter liquid samples on the surface of a glass or silicon substrate by combining chemical surface patterning with electronically addressable microheater arrays. Hydrophilic lanes designate the possible routes for liquid migration while activation of specific heater elements determines the trajectories. The induced temperature fields spatially modulate the liquid surface tension thereby providing electronic control over the direction, timing, and flow rate of continuous streams or discrete drops. Temperature maps can be programed to move, split, trap, and mix ultrasmall volumes without mechanically moving parts and with low operating voltages of $2-3 \mathrm{~V}$. This method of fluidic actuation allows direct accessibility to liquid samples for handling and diagnostic purposes and provides an attractive platform for palm-sized and battery-powered analysis and synthesis. (C) 2003 American Institute of Physics.
\end{abstract}

[DOI: $10.1063 / 1.1537512$ ]

Miniaturized automated systems for liquid routing, mixing, analysis, and synthesis are rapidly expanding diagnostic capabilities in medicine, genomic research, and material science. ${ }^{1}$ Liquid flow in microchannels can be regulated by pressure gradients, ${ }^{2}$ thermocapillary pumping, ${ }^{3}$ electrokinetic forces, ${ }^{4,5}$ or magnetohydrodynamic pumping. ${ }^{6,7}$ Electrowetting ${ }^{8,9}$ and dielectrophoresis ${ }^{10}$ have also been used to move droplets on an open surface. These techniques typically require high operating voltage and high electrolyte concentrations. We demonstrate a different method for liquid handling and transport that uses programmable surface temperature distributions, in conjunction with chemical substrate patterning, to provide electronic control over the direction, timing, and flow rate. This method capitalizes on the large surface-to-volume ratio inherent in microscale systems since the gas-liquid and liquid-solid surface energies are modulated to induce and confine flow. It works equally well with polar or nonpolar liquids, requires no mechanically moving parts and operates at very low voltages. The open architecture is best suited to liquids of low volatility. Encapsulation schemes that retain the free liquid-air interfaces can minimize evaporative loss.

Local heating of a liquid film at a position $\mathbf{x}$ reduces the surface tension $\gamma(\mathbf{x})$ to produce a thermocapillary shear stress $\tilde{\tau} \cdot \hat{n}=\boldsymbol{\nabla} \gamma=(\partial \gamma / \partial T) \boldsymbol{\nabla} T$ that pulls liquid toward regions of cooler surface temperature $T .^{11-13}$ Since $\partial \gamma / \partial T$ is essentially temperature independent for all liquids, the driving force and flow direction are proportional to $\nabla T$. For a thin flat liquid layer, the average flow speed and flow rate (per unit width) are given by $\boldsymbol{\nu}(\mathbf{x})=h(\mathbf{x}, t) \tilde{\tau} \cdot \hat{n} / 2 \mu(\mathbf{x})$ and $\mathbf{Q}(\mathbf{x}, t)=h(\mathbf{x}, t) \boldsymbol{\nu}(\mathbf{x}, t)$, where $h(\mathbf{x}, t)$ is the film thickness and $\mu(\mathbf{x})$ the local viscosity. This phenomenon forms the basis of our microfluidic device for actuating continuous streams and discrete droplets.

\footnotetext{
a) Author to whom correspondence should be addressed; electronic mail: stroian@princeton.edu
}

The sample layout ${ }^{14}$ for driving continuous streams is shown in Fig. 1(a). Hydrophilic stripes connect pairs of 4.5$\mathrm{mm}$-wide square reservoir pads; the gray areas are chemically treated to repel the liquid. ${ }^{15,16}$ A constant temperature gradient $d T / d x$ is generated by an embedded heating resistor (vertical black line) on the left and a cooling block (dotted rectangle) on the right. Figure 1(b) depicts a microstream emerging from a reservoir into a hydrophilic stripe subject to a streamwise temperature gradient. The liquids used were polydimethyl-siloxane (PDMS, $\mu=5$ and $20 \mathrm{mPas}, \gamma$ $=20.6 \mathrm{mN} / \mathrm{m}$, and $d \gamma / d T=-0.060 \mathrm{mN} / \mathrm{m}^{\circ} \mathrm{C}$ at $25^{\circ} \mathrm{C}$ ) and dodecane $(\mu=1.35 \mathrm{mPas}, \quad \gamma=25.5 \mathrm{mN} / \mathrm{m}, \quad$ and $d \gamma / d T$ $=-0.091 \mathrm{mN} / \mathrm{m}^{\circ} \mathrm{C}$ at $\left.25^{\circ} \mathrm{C}\right)$.

The speed of a continuous microstream depends on its length $L$, channelwidth $w, d T / d x$, and the deposited volume $V_{s}$. We have obtained a flow speed of $600 \mu \mathrm{m} / \mathrm{s}$ for PDMS $\left(\mu=5 \mathrm{mPa}\right.$ a $\left.\quad 25^{\circ} \mathrm{C}\right)$ with $d T / d x=1.44{ }^{\circ} \mathrm{C} / \mathrm{mm}, \quad w$ $=800 \mu \mathrm{m}$, and $V_{s}=8 \mu \mathrm{l}$. Flow speeds higher than $1 \mathrm{~mm} / \mathrm{s}$ can be obtained with smaller $\mu$, larger $\partial \gamma / \partial T$, and narrower, continuously fed reservoirs. Figure 2(a) shows the position
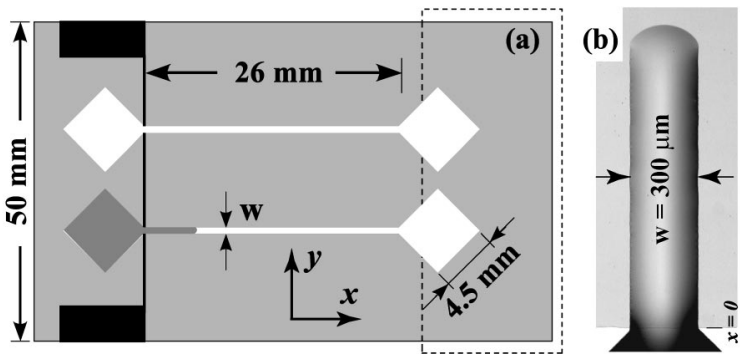

FIG. 1. (a) Layout of a chemically patterned silicon sample with uniform temperature gradient used for moving continuous streams. Gray areas are hydrophobic, white areas hydrophilic. Liquid $(2-8 \mu \mathrm{l})$ deposited on a diamond-shaped reservoir pad is propelled on a microstripe (width 100-800 $\mu \mathrm{m})$ due to the thermocapillary stress. The black rectangles are electrical contact pads connecting to the subsurface heating resistor (black line). The dashed rectangle denotes the cooling block. (b) Top-view optical micrograph of a rivulet moving on a $300-\mu \mathrm{m}$-wide channel. 

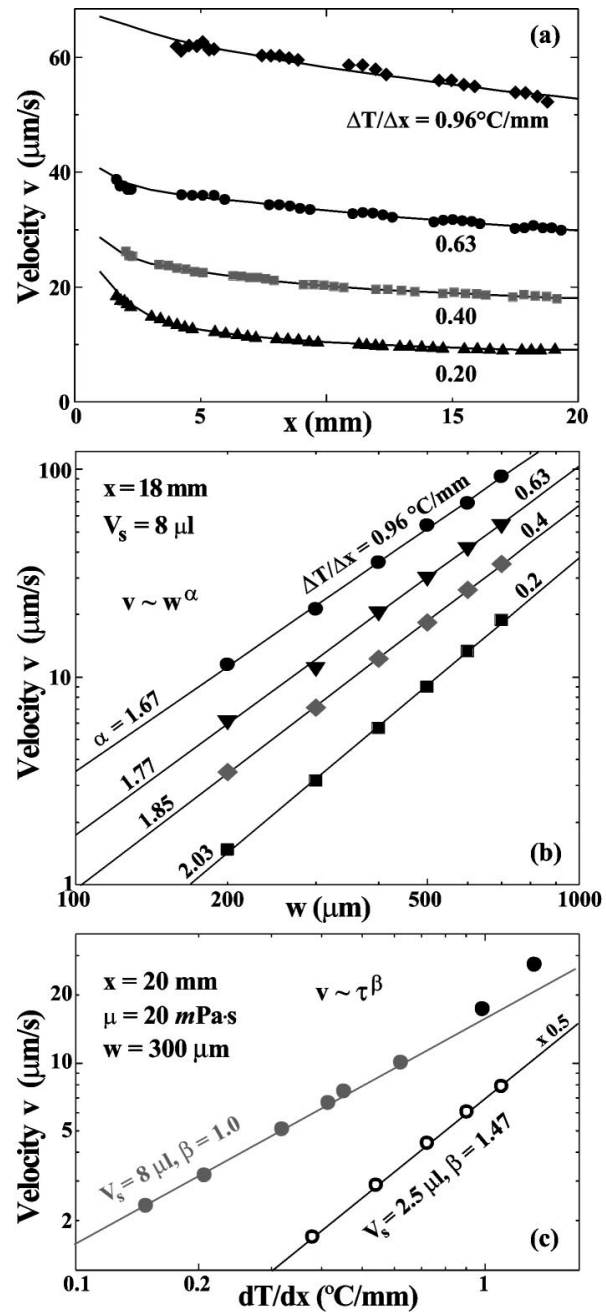

FIG. 2. Front speed of continuous streams. (a) Position dependence for four temperature gradients on a 500- $\mu \mathrm{m}$-wide stripe. Symbols: experimental data; solid lines: simulations. The film thickness at the stripe inlet was treated as a fitting parameter $\left(h_{0}=40 \pm 2 \mu \mathrm{m}\right)$. (b) Dependence on $w$ for four thermal gradients. (c) Dependence on $d T / d x$ for $w=300 \mu \mathrm{m}$.

dependence of the front speed for PDMS ( $\mu=20 \mathrm{mPa}$ ) and four different gradients. The solid lines represent numerical simulations of the front speed obtained from a lubrication equation for the evolution of centerline film thickness $h(x, t)$ according to

$h_{t}+\left[\frac{2 \tau h^{2}}{5 \mu}+\frac{64 h^{3}}{315 \mu}\left(\gamma h_{x x}\right)_{x}-\frac{192 h^{3}}{105 \mu w^{2}}(\gamma h)_{x}\right]_{x}=0$,

where subscripts denote partial differentiation. The film shape and speed are determined by the thermocapillary driving stress (term 2), capillary forces due to streamwise and lateral surface curvature (terms 3 and 4), and the temperature-dependent viscosity. ${ }^{15}$ The agreement with experiment is excellent. The observed decrease in speed shown in Fig. 2(a) is caused by the decrease in capillary forces ${ }^{16}$ and the increase in viscosity with distance. The relevant dimensionless numbers (based on parameter values at the inlet $x=0)$ are $(l / w)^{2}$, where $l=\left(\gamma h^{3} / 3 \mu v\right)^{1 / 3}$ is the dynamic capillary length, ${ }^{17}$ and $\tau / p_{0}$ where $p_{0}$ is the reservoir pressure. ${ }^{15}$ For $|\tau| / p_{0} \ll 1$, the inlet film height $h_{0}$ is controlled by $p_{0}$, which is essentially proportional to $V_{s} \cdot{ }^{16} \mathrm{~A}$ scaling analysis ${ }^{15}$ then gives $\nu \sim w^{2} \tau V_{s} / \mu$. In the opposite limit Downloaded 14 Oct 2009 to 131.155 .115 .10 . Redistribution subject

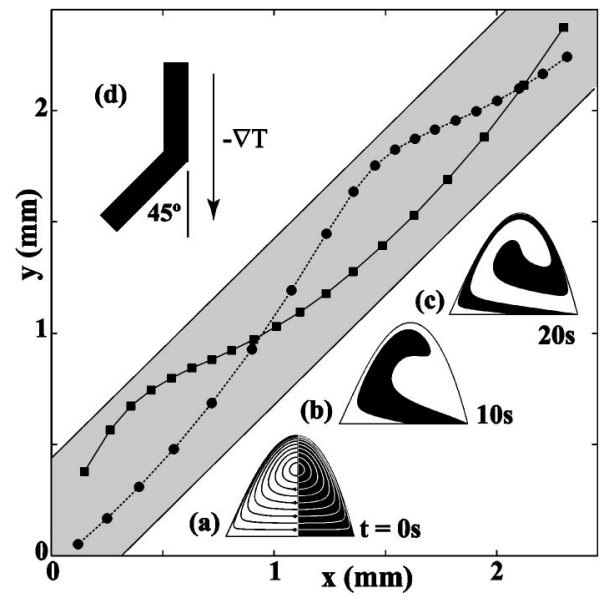

FIG. 3. (a)-(c) Mixing of two liquids (black and white) by thermocapillary convection induced by a transverse temperature gradient. The stripe is 500 $\mu \mathrm{m}$ wide, $h_{0}=20 \mu \mathrm{m}, d T / d y=4{ }^{\circ} \mathrm{C} / \mathrm{mm}$, and $\mu=20 \mathrm{mPa}$. The curves shown in (b) represent the streamlines of the convective flow. (d) Experimental positions $[x(t), y(t)]$ of 5- $\mu$ m-diam tracer particles in a rivulet flowing at a $45^{\circ}$ angle from the direction of $\nabla T(w=530 \mu \mathrm{m}$ and $\mu$ $=18 \mathrm{mPas}$ ). The time increment between subsequent data points is $\Delta t$ $=6 \mathrm{~s}$. The gray band signifies a portion of the slanted hydrophilic stripe.

$|\tau| / p_{0} \gg 1, \tau$ determines the inlet height ${ }^{15}$ and the front speed scales as $\nu \sim(w \tau)^{3 / 2} / \mu$. Figure 2(b) shows experimental data and least-square fits for the front speed as a function of $w$ at $x=18 \mathrm{~mm}$. To a good approximation, the data follow a power law $\nu \sim w^{\alpha}$, where the exponents $\alpha$ confirm the trend from 2 to 3/2. The dependence of the front speed on $d T / d x$ shown in Fig. 2(c) also follows the scaling predictions $v \sim \tau^{\beta}$, where $\beta=1$ and 1.47. The two data sets illustrate the transition from reservoir to shear-dominated regimes. For intermediate values of $|\tau| / p_{0}$, the flow speed does not conform to power laws but can only be determined by full numerical simulations. ${ }^{15}$

Mixing poses a difficulty in microfluidic devices due to the absence of turbulent convection. Figures 3(a)-3(c) depict computed convection patterns obtained with a purely transverse thermal gradient $d T / d y$ in the absence of diffusion. The interfacial area $A(t)$ between the two liquids increases at an essentially constant rate by a factor of 150 in just $30 \mathrm{~s}$. Simulations including molecular diffusion with coefficient $D=10^{-12} \mathrm{~m}^{2} / \mathrm{s}$ show a reduction in the mixing time $t_{\text {mix }}$ by three orders of magnitude compared to purely diffusive mixing. The presence of both convection and diffusion leads to a nonmonotonic scaling of $t_{\text {mix }}$ with $D$ similar to Taylor-Aris dispersion. ${ }^{18-20}$ Since thermocapillary flow is proportional to $h(\mathbf{x}, t)$, even faster mixing can be obtained by directing the flow onto a wider hydrophilic patch that supports thicker films. By imposing an additional thermal gradient $d T / d x$ parallel to the microstripe, the streamlines follow helical paths thereby significantly increasing the interfacial area between merging streams. Figure 3(d) presents experimental flow patterns on a hydrophilic stripe inclined by $45^{\circ}$ to the direction of the thermal gradient. The solid symbols designate the measured trajectories $[x(t), y(t)]$ of tracer particles convected with the flow. A larger spacing between subsequent points signifies a faster flow near the air-liquid interface-a smaller spacing indicates slower flow near the solid substrate.

The resistor and channel layout used for actuation of

license or copyright; see http://apl.aip.org/apl/copyright.jsp 


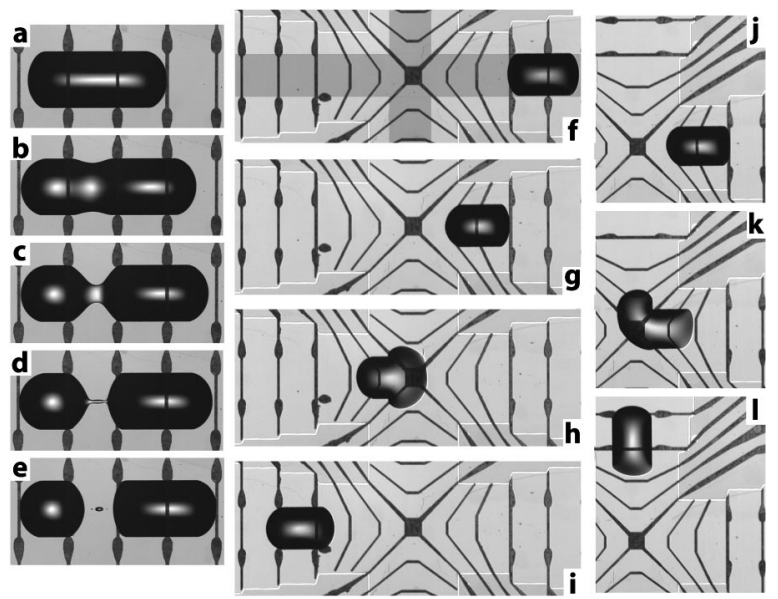

FIG. 4. (a)-(e) Thermally induced splitting of a dodecane drop on a partially wetting stripe $(w=1000 \mu \mathrm{m})$. The voltage applied to the microheater $(155 \Omega)$ was $2.5 \mathrm{~V}$. The images were recorded at $t=0,6.0,7.5,8.0$, and 8.5 s. (f)-(i) Dodecane drop propelled through an intersection outlined by the dark gray pattern $(w=1000 \mu \mathrm{m}$, time lapse $104 \mathrm{~s})$. (j)-(l) Dodecane drop turning a $90^{\circ}$ corner (time lapse $164 \mathrm{~s}$ ).

discrete drops is shown in Fig. 4. The surface temperature is electronically programmed through an array of embedded heating resistors (light gray). Discrete drops or continuous streams can be moved along hydrophilic pathways (orange) and directed around corners. Local temperature control allows splitting of a liquid stream into droplets of predefined volume. Figures 4(a)-4(e) show the generation of a doublet from a single drop. The rate of film thinning above a heated resistor is essentially proportional to the heating power, but independent of $w$ and the film thickness. ${ }^{21}$ The rupture of the small connecting thread leaves behind satellite droplets, which can be absorbed by dispatching one of the main drops to collect the residue. The electrical power used to split and propel drops of dodecane was typically less than $40 \mathrm{~mW}$ per resistor. The power can be reduced by at least one order of magnitude by using a polymeric substrate of low thermal conductivity instead of glass. ${ }^{22}$ Battery operation of this microfluidic device is, therefore, practicable.

Figures 4(f)-4(1) depict electronic propulsion of discrete droplets along partially wetting microstripes. The heating elements are slightly narrower near the microstripe edges. These constrictions increase the local resistive heating, which causes a slightly elevated temperature at the stripe edges. This helps center the streaming drops and films laterally. Figures 4(f)-4(i) show a dodecane drop moving from right to left through an intersection of two partially wetting, $1000-\mu \mathrm{m}$-wide stripes on a glass substrate. Figures 4(j)-4(1) show a drop being pulled around a corner. The average droplet speed $\nu_{d}$ is controlled by the electronic switching interval-in Figs. 4(f) -4 (i) $\nu_{d}=56 \mu \mathrm{m} / \mathrm{s}$ and in Figs. 4(j)$4(1), v_{d}=26 \mu \mathrm{m} / \mathrm{s}$. In these series, the applied voltage was $2.36 \mathrm{~V}$ and the heater resistance $140 \Omega$. The control algorithm involved sequentially powering one resistor ahead of the drop $(20 \mathrm{~mW})$ and two resistors behind it $(\leqslant 40 \mathrm{~mW}$ each in a ramp-like fashion). The drop position is, therefore, known to a precision equal to the resistor width, which is advantageous for the simultaneous routing of a multitude of droplets. On completely wetting surfaces, a thin residue film can trail a moving droplet since the receding contact angle is vanishingly small. Such residual films, which can cross contaminate liquid samples, can be eliminated, by making the surface pathways partially wetting.

We have demonstrated that electronically addressable heating arrays coupled with chemical surface patterning can be used to actuate and manipulate continuous streams or discrete drops of liquid on a solid substrate. Numerical simulations for the flow speed of continuous microstreams are in excellent agreement with experiment. Electronic control enables transport with preset velocity, efficient mixing of stationary or moving liquids, and merging or splitting of liquids into specified volumes. Temperature maps can be programmed to trap drops at a specified location for analysis and synthesis. As the presence of an overlying liquid film affects the thermal response time of the resistors, they can be used as position sensors providing feedback control. ${ }^{22}$ This device can also serve as a chemical sensor since the liquid is in continuous contact with the ambient vapor phase. The variety of tasks that can be accomplished with highresolution thermal maps should, therefore, inspire alternative designs for pocket-sized diagnostic devices.

This work is supported by NSF grant CTS-0088774, MRSEC grant DMR-9809483, a NJCST grant, and an NDSEG fellowship (J.M.D.).

${ }^{1}$ D. Meldrum, Genome Res. 10, 1288 (2000).

${ }^{2}$ P. Gravesen, J. Branebjerg, and O. S. Jensen, J. Micromech. Microeng. 3, 168 (1993).

${ }^{3}$ T. S. Sammarco and M. A. Burns, AIChE J. 45, 350 (1999).

${ }^{4}$ J. M. Ramsey, S. C. Jacobson, and M. R. Knapp, Nat. Med. (N.Y.) 1, 1093 (1995).

${ }^{5}$ G. H. W. Sanders and A. Manz, Trends Anal. Chem. 19, 364 (2000).

${ }^{6}$ W. Ritchie, Philos. Trans. R. Soc. London 122, 279 (1832).

${ }^{7}$ J. Jang and S. S. Lee, Sens. Actuators A 80, 84 (2000).

${ }^{8}$ J. Lee and C.-J. Kim, J. Microelectromech. Syst. 9, 171 (2000).

${ }^{9}$ M. G. Pollack, R. B. Fair, and A. D. Shenderov, Appl. Phys. Lett. 77, 1725 (2000).

${ }^{10}$ T. B. Jones, M. Gunji, M. Washizu, and M. J. Feldman, J. Appl. Phys. 89, 1441 (2001)

${ }^{11}$ L. G. Leal, Laminar and Convective Transport Processes (ButterworthHeinemann, Boston, 1992).

${ }^{12}$ V. G. Levich, Physicochemical Hydrodynamics (Prentice-Hall, Englewood Cliffs, NJ, 1962).

${ }^{13}$ V. Ludviksson and E. N. Lightfoot, AIChE J. 17, 1166 (1971).

${ }^{14} \mathrm{Si}$ wafers were first coated with $200 \mathrm{~nm} \mathrm{SiN}_{x}$ and $200 \mathrm{~nm} \mathrm{SiO}_{2}$, deposited by plasma enhanced chemical vapor deposition (PECVD) at $250{ }^{\circ} \mathrm{C}$. A $100 \mathrm{~nm}$ Au layer was then deposited by an electron beam evaporation (EBE) and patterned into heating elements using a lift-off technique. The heating elements were passivated with $600 \mathrm{~nm} \mathrm{PECVD} \mathrm{SiO}_{2}$, on top of which the chemical pattern was defined in a layer of perfluorooctyltrichlorosilane (PFOTS) by photolithography. Ti heaters and Au contacts were deposited on Corning 1737 glass slides by EBE. The hydrophilic stripes were defined on a $200 \mathrm{~nm}$ PECVD $\mathrm{SiO}_{2}$ layer using PFOTS.

${ }^{15}$ A. A. Darhuber, J. M. Davis, S. M. Troian, and W. Reisner, Phys. Fluids. (submitted).

${ }^{16}$ A. A. Darhuber, S. M. Troian, and W. Reisner, Phys. Rev. E 64, 1603 (2001).

${ }^{17}$ S. M. Troian, E. Herbolzheimer, S. A. Safran, and J. F. Joanny, Europhys. Lett. 10, 25 (1989).

${ }^{18}$ G. I. Taylor, Proc. R. Soc. London, Ser. A 219, 186 (1953).

${ }^{19}$ R. Aris, Proc. R. Soc. London, Ser. A 235, 67 (1956).

${ }^{20}$ A. A. Darhuber, J.-Z. Chen, J. M. Davis, and S. M. Troian (unpublished).

${ }^{21}$ A. A. Darhuber and S. M. Troian (unpublished).

${ }^{22}$ A. A. Darhuber, S. M. Troian, and S. Wagner, J. Appl. Phys. 91, 5686 (2002) 